Pacific Journal of Mathematics

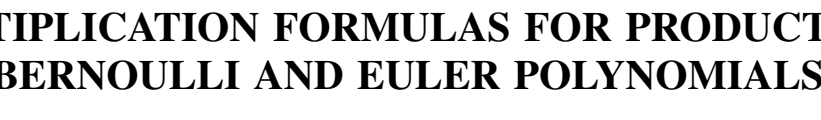




\title{
MULTIPLICATION FORMULAS FOR PRODUCTS OF BERNOULLI AND EULER POLYNOMIALS
}

\author{
L. Carlitz
}

1. Put

$$
\frac{t e^{x \ell}}{e^{\iota}-1}=\sum_{n=0}^{\infty} B_{n}(x) \frac{t^{n}}{n !}, \frac{2 e^{x \iota}}{e^{t}+1}=\sum_{n=0}^{\infty} E_{n}(x) \frac{t^{n}}{n !} .
$$

The following multiplication formulas are familiar [5, pp. 18, 24]:

$$
\begin{aligned}
& B_{m}(k x)=k^{m-1} \sum_{r=0}^{k-1} B_{m}\left(x+\frac{k}{r}\right) \\
& E_{m}(k x)=k^{m} \sum_{r=0}^{k-1}(-1)^{r} E_{m}\left(x+\frac{k}{r}\right)
\end{aligned}
$$

Let $\bar{B}_{m}(x), \bar{E}_{m}(x)$ denote, respectively, the Bernoulli and Euler functions defined by

$$
\begin{aligned}
& \bar{B}_{m}(x)=B_{m}(x)(0 \leq x<1), \bar{B}_{m}(x+1)=\bar{B}_{m}(x), \\
& \bar{E}_{m}(x)=E_{m}(x)(0 \leq x<1), \bar{E}_{m}(x+1)=-\bar{E}_{m}(x), \quad(m \geq 1) .
\end{aligned}
$$

Then $\bar{B}_{m}(x)$ and $\bar{E}_{m}(x)$ also satisfy the multiplication formulas (1.2), (1.3).

In this note we obtain some generalizations of (1.2) and (1.3) suggested by a recent result of Mordell [4]. In extending some results of Mikolás [3], Mordell proves the following theorem. Let $f_{1}(x), \cdots, f_{n}(x)$ denote functions of $x$ of period 1 that satisfy the relations

$$
\sum_{r=0}^{k-1} f_{i}\left(r+\frac{r}{k}\right)=C_{i}^{(h)} f_{i}(k x) \quad(i=1, \cdots, n),
$$

where $C_{i}^{(k)}$ is independent of $x$. Let $a_{1}, \cdots, a_{n}$ be positive integers that are relatively prime in pairs. Then if the integrals exist and $A=a_{1} a_{2} \cdots a_{n}$,

$$
\begin{aligned}
& \int_{0}^{A} f_{1}\left(\frac{x}{a_{1}}\right) f_{2}\left(\frac{x}{a_{2}}\right) \cdots f_{n}\left(\frac{x}{a_{n}}\right) d x \\
& \quad=A \int_{0}^{1} f_{1}\left(\frac{A x}{a_{1}}\right) f_{2}\left(\frac{A x}{a_{2}}\right) \cdots f_{n}\left(\frac{A x}{a_{n}}\right) d x \\
& \quad=C_{1}^{\left(a_{1}\right)} C_{2}^{\left(a_{2}\right)} \cdots C_{n}^{\left(a_{n}\right)} \int_{0}^{1} f_{1}(x) f_{2}(x) \cdots f_{n}(x) d x .
\end{aligned}
$$

Received November 24, 1958. 


\section{We first prove}

THEOREM 1. Let $n \geq 1 ; m_{1}, \cdots, m_{n} \geq 1 ; a_{1}, a_{2}, \cdots, a_{n}$ positive integers that are relative prime in pairs; $A=a_{1}, a_{2}, \cdots, a_{n}$. Then

$$
\begin{aligned}
& \sum_{r=0}^{k A-1} \bar{B}_{m_{1}}\left(x_{1}+\frac{r}{a_{1} k}\right) \bar{B}_{m_{2}}\left(x_{2}+\frac{r}{a_{2} k}\right) \cdots \bar{B}_{m_{n}}\left(x_{n}+\frac{r}{a_{n} k}\right) \\
& =C \sum_{r=0}^{k-1} \bar{B}_{m_{1}}\left(a_{1} x_{1}+\frac{r}{k}\right) \bar{B}_{m_{2}}\left(a_{2} x_{2}+\frac{r}{k}\right) \cdots \bar{B}_{m_{n}}\left(a_{n} x_{n}+\frac{r}{k}\right),
\end{aligned}
$$

where

$$
C=\boldsymbol{a}_{1}^{1-m_{1}} \boldsymbol{a}_{2}^{1-m_{2}} \cdots \boldsymbol{a}_{n}^{1-m_{n}} .
$$

In the first place for $n=1$ it follows from (1.2) for arbitrary $a \geq 1$ that

$$
\begin{aligned}
\sum_{r=0}^{k a-1} \bar{B}_{m}\left(x+\frac{r}{a k}\right) & =\sum_{r=0}^{k-1} \sum_{s=0}^{a-1} \bar{B}_{m}\left(r+\frac{s}{a}+\frac{r}{a k}\right) \\
& =\sum_{r=0}^{k-1} \bar{B}_{m}\left(a x+\frac{r}{k}\right),
\end{aligned}
$$

which agrees with (2.1).

For the general case, let $S$ denote the left member of (2.1). Put

$$
A_{\mathrm{s}}=a_{1} a_{2} \cdots a_{\mathrm{s}} \quad(1 \leq s \leq n)
$$

and replace $r$ by $s k A_{n-1}+r$. Then

$$
\begin{gathered}
S=\sum_{r=0}^{k A_{n-1}{ }^{-1}} \bar{B}_{m_{1}}\left(x_{1}+\frac{r}{a_{1} k}\right) \cdots \bar{B}_{m_{n-1}}\left(x_{n-1}+\frac{r}{a_{n-1} k}\right) \\
\cdot \sum_{s=0}^{a_{n}{ }^{-1}} \bar{B}_{m_{n}}\left(x_{n}+\frac{A_{n-1} s}{a_{n}}+\frac{r}{a_{n} k}\right) \\
=\sum_{r=0}^{k A_{n-1}-1} \bar{B}_{m_{1}}\left(x_{1}+\frac{r}{a_{1} k}\right) \cdots \bar{B}_{m_{n-1}}\left(x_{n-1}+\frac{r}{a_{n-1} k}\right) \\
\cdot \sum_{s=0}^{a_{n}-^{-1}} \bar{B}_{m_{n}}\left(x_{n}+\frac{s}{a_{n}}+\frac{r}{a_{n} k}\right) \\
=a_{n}^{1-m_{n}} \sum_{r=0}^{k A_{n-1}-1} \bar{B}_{m_{1}}\left(x_{1}+\frac{r}{a_{1} k}\right) \cdots \bar{B}_{m_{n-1}}\left(x_{n-1}+\frac{r}{a_{n-1} k}\right) \\
\cdot \bar{B}_{m_{n}}\left(a_{n} x_{n}+\frac{r}{k}\right) .
\end{gathered}
$$

Continuing in this way we get 


$$
\begin{gathered}
S=a_{n-1}^{1-m} n-1 a_{n}^{1-m_{n}} \sum_{r=0}^{k A_{n-2}{ }^{-1}} \bar{B}_{m_{1}}\left(x_{1}+\frac{r}{a_{1} k}\right) \cdots \bar{B}_{m_{n-2}}\left(x_{n-2}+\frac{r}{a_{n-2} k}\right) \\
\cdot \bar{B}_{m_{n-1}}\left(a_{n-1} x_{n-1}+\frac{r}{k}\right) \bar{B}_{m_{n}}\left(a_{n} x_{n}+\frac{r}{k}\right) \\
=a_{1}^{1-m} 1 \cdots a_{n}^{1-m_{n}} \sum_{r=0}^{k-1} \bar{B}_{m_{1}}\left(a_{1} x_{1}+\frac{r}{k}\right) \bar{B}_{2}\left(a_{2} x_{2}+\frac{r}{k}\right) \\
\cdots \bar{B}_{m_{n}}\left(a_{n} x_{n}+\frac{r}{k}\right) .
\end{gathered}
$$

For $k=1,(2,1)$ reduces to

$$
\begin{gathered}
\sum_{r=0}^{A-1} \bar{B}_{m_{1}}\left(x_{1}+\frac{r}{a_{1}}\right) \bar{B}_{2}\left(x_{2}+\frac{r}{a_{2}}\right) \cdots \bar{B}_{n}\left(x_{n}+\frac{r}{a_{n}}\right) \\
=C \cdot \bar{B}_{m_{1}}\left(a_{1} x_{1}\right) \bar{B}_{m_{2}}\left(a_{2} x_{2}\right) \cdots \bar{B}_{m_{n}}\left(a_{n} x_{n}\right),
\end{gathered}
$$

where $C$ is defined by $(2.2)$; (2.3) may be considered a direct generalization of (1.2).

We remark that a formula like (2.1) holds for any set of functions satisfying (1.4).

We note also that the formula (2.2) can be proved by means of the Chinese remainder theorem. This remarks applies also to formulas (3.4) and (4.8) below.

\section{In the next place we have}

THeOREM 2. Let $n$ be odd and $\geq 1 ; m_{1}, \cdots, m_{n} \geq 1 ; a_{1}, a_{2}, \cdots, a_{n}$ positive odd integers that are relatively prime in pairs; $A=a_{1} a_{2} \cdots a_{n}$; k odd $\geq 1$. Then

$$
\begin{aligned}
& \sum_{r=0}^{k A-1}(-1)^{r} \bar{E}_{m_{1}}\left(x_{1}+\frac{r}{a_{1} k}\right) \cdots \bar{E}_{m_{n}}\left(x_{n}+\frac{r}{a_{n} k}\right) \\
& =C^{\prime} \sum_{r=0}^{k-1}(-1)^{r} \bar{E}_{m_{1}}\left(a_{1} x_{1}+\frac{r}{k}\right) \cdots \bar{E}_{m_{n}}\left(a_{n} x_{n}+\frac{r}{k}\right),
\end{aligned}
$$

where

$$
C^{\prime}=a_{1}^{-m_{1}} a_{2}^{-m_{2}} \cdots a_{n}^{-m_{n}} .
$$

The proof is similar to that of Theorem 1, but makes use of (1.3) in place of (1.2); also the formula

$$
\bar{E}_{m}(x+r)=(-1)^{r} \bar{E}_{m}(x)
$$

is needed. 
For $n=1$ and $a$ odd, we have

$$
\begin{aligned}
& \sum_{r=0}^{k a-1}(-1)^{r} \bar{E}_{m_{1}}\left(x+\frac{r}{a k}\right)=\sum_{r=0}^{k-1}(-1)^{s k} \bar{E}_{m}\left(x+\frac{s}{a}+\frac{r}{a k}\right) \\
& =a^{-m} \sum_{r=0}^{k-1}(-1)^{r} \bar{E}_{m}\left(a x+\frac{r}{k}\right),
\end{aligned}
$$

which agrees with (3.1). For the general case let $S^{\prime}$ denote the left member of (3.1). Then

$$
\begin{aligned}
S^{\prime}= & \sum_{r=0}^{k A_{n-1}{ }^{-1}} \sum_{s=0}^{a_{n}{ }^{-1}}(-1)^{r+s} \bar{E}_{m_{1}}\left(x_{1}+\frac{s A_{n-1}}{a_{1}}+\frac{r}{a_{1} k}\right) \cdots \\
& \cdot \bar{E}_{m_{n-1}}\left(x_{n-1}+\frac{s A_{n-1}}{a_{n-1}}+\frac{r}{a_{n-1} k}\right) \\
& \cdot \bar{E}_{m_{n}}\left(x_{n}+\frac{s A_{n-1}}{a_{n}}+\frac{r}{a_{n} k}\right) .
\end{aligned}
$$

If we put

$$
s A_{n-1}=q a_{n}+t \quad\left(0 \leq t<a_{n}\right),
$$

then $s \equiv q+t(\bmod 2)$, so that

$$
\bar{E}_{m_{n}}\left(x_{n}+\frac{s A_{n-1}}{a_{n}}+\frac{r}{a_{n} k}\right)=(-1)^{q} \bar{E}_{m_{n}}\left(x_{n}+\frac{t}{a_{n}}+\frac{r}{a_{n} k}\right) .
$$

Since $n$ is odd we therefore get

$$
\begin{aligned}
& S^{\prime}= \sum_{r=0}^{k A_{n-1}{ }^{-1}}(-1)^{r} \bar{E}_{m_{1}}\left(x_{1}+\frac{r}{a_{1} k}\right) \cdots \bar{E}_{m_{n-1}}\left(x_{n-1}+\frac{r}{a_{n-1} k}\right) \\
& \cdot \sum_{l=0}^{a_{n} n^{-1}}(-1)^{t} \bar{E}_{m_{n}}\left(x_{n}+\frac{t}{a_{n}}+\frac{r}{a_{n} k}\right) \\
&=\sum_{r=0}^{k A_{n-1}{ }^{-1}}(-1)^{r} \bar{E}_{m_{1}}\left(x_{1}+\frac{r}{a_{1} k}\right) \cdots \bar{E}_{m_{n-1}}\left(x_{n-1}+\frac{r}{a_{n-1} k}\right) \\
& \cdot a_{n}^{-m_{n}} \bar{E}_{m_{n}}\left(a_{n} x_{n}+\frac{r}{k}\right) .
\end{aligned}
$$

Continuing in this way we ultimately reach (3.1).

For $k=1$, (3.1) becomes

$$
\begin{aligned}
& \sum_{r=0}^{A-1}(-1)^{r} \bar{E}_{m_{1}}\left(x_{1}+\frac{r}{a_{1}}\right) \cdots \bar{E}_{m_{n}}\left(x_{n}+\frac{r}{a_{n}}\right) \\
& =C^{\prime} E_{m_{1}}\left(a_{1} x_{1}\right) \cdots E_{m_{n}}\left(a_{n} x_{n}\right),
\end{aligned}
$$


subject to the conditions of the theorem.

4. Theorem 2 can be extended further by introducing the "Eulerian" polynomial [2] $\phi_{m}(x, \rho)$ defined by

$$
\frac{1-\rho}{1-\rho e^{t}} e^{x t}=\sum_{m=0}^{\infty} \phi_{m}(x, \rho) \frac{t^{m}}{m !} \quad(\rho \neq 1) .
$$

In particular $\phi_{m}(x,-1)=E_{m}(x)$.

We shall assume that the parameter $\rho$ is an $f$ th root of unity. It follows easily from (4.1) that

$$
\phi_{m-1}(k x, \rho)=\frac{(\rho-1) f^{m-1}}{m} \sum_{r=0}^{j-1} \rho^{r} B_{m}\left(x+\frac{r}{f}\right) .
$$

We accordingly define the function $\bar{\phi}_{n}(x, \rho)$ by means of

$$
\bar{\phi}_{m-1}(k x, \rho)=\frac{(\rho-1) e^{m-1}}{m} \sum_{r=0}^{j-1} \rho^{r} \bar{B}_{m}\left(x+\frac{r}{f}\right) .
$$

It follows from (4.3) that

$$
\bar{\phi}_{n}(x+1, \rho)=\rho^{-1} \bar{\phi}_{n}(x, \rho),
$$

so that if $\rho$ is a primitive $f$ th root of unity, $\bar{\phi}_{n}(x, \rho)$ has period $f$. Also by means of (4.1) we readily obtain the multiplication theorem [1] valid for $k \equiv 1(\bmod f)$

$$
\sum_{r=0}^{k-1} \rho^{r} \phi_{m}\left(x+\frac{r}{k}, \rho\right)=k^{-m} \phi_{m}(k x, \rho)
$$

and consequently

$$
\sum_{r=0}^{k-1} \rho^{r} \bar{\phi}_{m}\left(x+\frac{r}{k}, \rho\right)=k^{-m} \bar{\phi}_{m}(k x, \rho) .
$$

We may now state

Theorem 3. Let $f>1, n \equiv 1(\bmod f) ; m_{1}, \cdots, m_{n} \geq 1, a_{1}, a_{2}, \cdots, a_{n}$ positive integers that are relatively prime in pairs and such that $a_{i} \equiv 1(\bmod f)$ for $i=1, \cdots, n$; also let $k \equiv 1(\bmod f)$. Then if $A=a_{1} a_{2} \cdots a_{n}$, we have

$$
\sum_{r=0}^{k A-1} \rho^{r} \bar{\phi}_{m_{1}}\left(x_{1}+\frac{r}{a_{1} k}, \rho\right) \cdots \bar{\phi}_{m_{n}}\left(x_{n}+\frac{r}{a_{n} k}, \rho\right)
$$




$$
=C^{\prime} \sum_{r=0}^{k-1} \rho^{r} \bar{\phi}_{m_{1}}\left(a_{1} x_{1}+\frac{r}{k}, \rho\right) \cdots \bar{\phi}_{m_{n}}\left(a_{n} x_{n}+\frac{r}{k}, \rho\right)
$$

where $C^{\prime}$ is defined by (3.2).

The proof is very much like that of Theorem 2 and will be omitted. We remark that for $k=1$, (4.7) becomes

$$
\begin{gathered}
\sum_{r=0}^{A-1} \rho^{r} \bar{\phi}_{m_{1}}\left(x_{1}+\frac{r}{a_{1}}, \rho\right) \cdots \bar{\phi}_{m_{n}}\left(x_{n}+\frac{r}{a_{n}}, \rho\right) \\
=C^{\prime} \bar{\phi}_{m_{1}}\left(a_{1} x_{1}, \rho\right) \cdots \bar{\phi}_{m_{n}}\left(a_{n} x_{n}, \rho\right) .
\end{gathered}
$$

\section{REFERENCES}

1. L. Carlitz, The multiplication formulas for the Bernoulli and Euler polynomials' Mathematics Magazine, 27 (1953), 59-64.

2. G. Frobenius, Uber die Bernoulli'schen Zahlen und die Euler'schen Polynome, Sitzungsberichte der Preussischen Akademie der Wissenschaften (1910), 809-847.

3. M. Mikolás, Integral formulas of arithmetical characteristics relating to the zetafunction of Hurwitz, Publicationes Mathematicae, 5 (1957), 44-53.

4. L. J. Mordell, Integral formulas of arithmetical character, Journal of the London Mathematical Society, 33 (1957), 371-375.

5. N. E. Nörlund, Vorlesungen über Differenzenrechnung, Berlin, 1924.

DUKE UNIVERSITY 


\section{PACIFIC JOURNAL OF MATHEMATICS}

\section{EDITORS}

\section{David Gilbarg}

Stanford University Stanford, California

\section{R. A. Beaumont}

University of Washington

Seattle 5, Washington

\section{A. L. Whiteman}

University of Southern California Los Angeles 7, California

L. J. Paige

University of California

Los Angeles 24, California

\section{ASSOCIATE EDITORS}

E. F. BECKENBACH
C. E. BURGESS
E. HEWITT
A. HORN

A. HORN

\author{
V. GANAPATHY IYER \\ R. D. JAMES \\ M. S. KNEBELMAN \\ L. NACHBIN
}

I. NIVEN

T. G. OSTROM

H. L. ROYDEN

M. M. SCHIFFER
E. G. STRAUS

G. SZEKERES

F. WOLF

K. YOSIDA

\section{SUPPORTING INSTITUTIONS}

\author{
UNIVERSITY OF BRITISH COLUMBIA \\ CALIFORNIA INSTITUTE OF TECHNOLOGY \\ UNIVERSITY OF CALIFORNIA \\ MONTANA STATE UNIVERSITY \\ UNIVERSITY OF NEVADA \\ OREGON STATE COLLEGE \\ UNIVERSITY OF OREGON \\ OSAKA UNIVERSITY \\ UNIVERSITY OF SOUTHERN CALIFORNIA
}

\author{
STANFORD UNIVERSITY \\ UNIVERSITY OF TOKYO \\ UNIVERSITY OF UTAH \\ WASHINGTON STATE COLLEGE \\ UNIVERSITY OF WASHINGTON \\ * * * * \\ AMERICAN MATHEMATICAL SOCIETY \\ CALIFORNIA RESEARCH CORPORATION \\ HUGHES AIRCRAFT COMPANY \\ SPACE TECHNOLOGY LABORATORIES
}

Mathematical papers intended for publication in the Pacific Journal of Mathematics should be typewritten (double spaced), and the author should keep a complete copy. Manuscripts may be sent to any one of the four editors. All other communications to the editors should be addressed to the managing editor, L. J. Paige at the University of California, Los Angeles 24, California.

50 reprints per author of each article are furnished free of charge; additional copies may be obtained at cost in multiples of 50 .

The Pacific Journal of Mathematics is published quarterly, in March, June, September, and December. The price per volume (4 numbers) is $\$ 12.00$; single issues, $\$ 3.50$. Back numbers are available. Special price to individual faculty members of supporting institutions and to individual members of the American Mathematical Society: $\$ 4.00$ per volume; single issues, $\$ 1.25$.

Subscriptions, orders for back numbers, and changes of address should be sent to Pacific Journal of Mathematics, 2120 Oxford Street, Berkeley 4, California.

Printed at Kokusai Bunken Insatsusha (International Academic Printing Co., Ltd.), No. 6, 2-chome, Fujimi-cho, Chiyoda-ku, Tokyo, Japan.

PUBLISHED BY PACIFIC IOURNAL OF MATHEMATICS, A NON-PROFIT CORPORATION

The Supporting Institutions listed above contribute to the cost of publication of this Journal, but they are not owners or publishers and have no responsibility for its content or policies. 


\section{Pacific Journal of Mathematics}

\section{Vol. 9, No. $3 \quad$ July, 1959}

Errett Albert Bishop, A minimal boundary for function algebras . . . . . . . . . . . . 629

John W. Brace, The topology of almost uniform convergence . . . . . . . . . . . . 643

Cecil Edmund Burgess, Chainable continua and indecomposability .......... 653

L. Carlitz, Multiplication formulas for products of Bernoulli and Euler

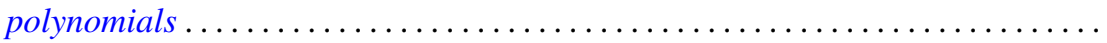

Eckford Cohen, A class of residue systems (mod $r$ ) and related arithmetical

functions. II. Higher dimensional analogues ....................

Shaul Foguel, Boolean algebras of projections of finite multiplicity . . . . . . . . . .

Richard Robinson Goldberg, Averages of Fourier coefficients .................

Seymour Goldberg, Ranges and inverses of perturbed linear operators .

Philip Hartman, On functions representable as a difference of convex functions ....

Milton Vernon Johns, Jr. and Ronald Pyke, On conditional expectation and

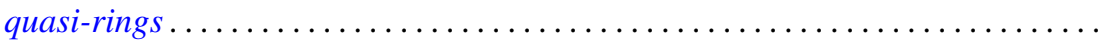

Robert Jacob Koch, Arcs in partially ordered spaces ....................

Gregers Louis Krabbe, A space of multipliers of type $L^{p}(-\infty, \infty) \ldots \ldots \ldots \ldots$

John W. Lamperti and Patrick Colonel Suppes, Chains of infinite order and their

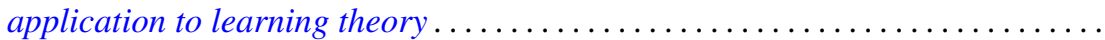

Edith Hirsch Luchins, On radicals and continuity of homomorphisms into Banach

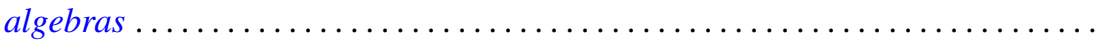

T. M. MacRobert, Multiplication formulae for the E-functions functions of their parameters.

Michael Bahir Maschler, Classes of minimal and representative domains and their kernel functions.

William Schumacher Massey, On the imbeddability of the real projective spaces in Euclidean space.

Thomas Wilson Mullikin, Semi-groups of class $\left(C_{0}\right)$ in $L_{p}$ determined by parabolic differential equations

Steven Orey, Recurrent Markov chains

Ernest Tilden Parker, On quadruply transitive groups ........ . .

Calvin R. Putnam, On Toeplitz matrices, absolute continuity, and unitary

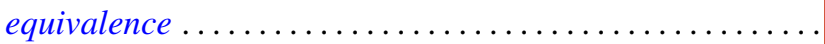

Helmut Heinrich Schaefer, On nonlinear positive operators.

Robert Seall and Marion Wetzel, Some connections between continued fractions and convex sets

Robert Steinberg, Variations on a theme of Chevalley

Olga Taussky and Hans Zassenhaus, On the similarity transformation between a

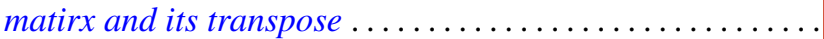

Emery Thomas, The suspension of the generalized Pontrjagin cohomology

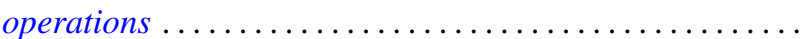

Joseph L. Ullman, On Tchebycheff polynomials ..................... 913

Richard Steven Varga, Orderings of the successive overrelaxation scheme ........ 925

Orlando Eugenio Villamayor, Sr., On weak dimension of algebras . 